\title{
Perioperative changes in peripheral regulatory $B$ cells of patients with esophageal cancer
}

\author{
JIAZHEN SHI ${ }^{1 *}$, SHIBAO LI ${ }^{1,2^{*}}$, YAN ZHOU ${ }^{1}$, LIXIN WANG $^{3}$, \\ JIANGTAO WEN ${ }^{1}$, YONGHONG WANG ${ }^{4}$ and ZHIHUA KANG ${ }^{2}$
}

\begin{abstract}
${ }^{1}$ Department of Laboratory Medicine, Lianyungang Hospital Affiliated to Bengbu Medical College, Lianyungang, Jiangsu 222006; ${ }^{2}$ Department of Laboratory Medicine, Huashan Hospital, Shanghai Medical School, Fudan University, Shanghai 200040; ${ }^{3}$ Department of Microbiology and Immunology, Medical School of Southeast University, Nanjing, Jiangsu 210029; ${ }^{4}$ Department of Cardiothoracic Surgery, Lianyungang Hospital Affiliated to Bengbu Medical College, Lianyungang, Jiangsu 222006, P.R. China
\end{abstract}

Received July 24, 2013; Accepted May 2, 2014

DOI: $10.3892 / \mathrm{mmr} .2014 .2347$

\begin{abstract}
Current treatments for esophageal cancer (EC) rely on tumor eradication by surgery or chemoradiotherapy. However, such treatments do not account for the assessment and adjustment of the immune status of the patients. Regulatory B cells (Bregs) have been confirmed as a negative regulatory subtype in B-cell populations. However, to the best of our knowledge, there have been no direct studies on Bregs in patients with EC. The present study enrolled sixty patients with EC and sixty healthy donors to detect the presence of Bregs in peripheral blood and to determine their clinical significance. The percentage of peripheral Bregs was measured using flow cytometry with fluorescence-labeled antibodies against cluster of differentiation (CD) 5, CD19, interleukin (IL)-10, forkhead box protein 3 (Foxp3) and transforming growth factor- $\beta 1$ (TGF- $\beta 1$ ) prior to and following radical surgery. The level of circulating Bregs in patients with EC was observed to be significantly higher than that in the healthy donors. However, this level was observed to decrease following surgery. The percentage of circulating TGF- $\beta$-producing Bregs and Foxp3-expressing Bregs in patients with EC also decreased following surgery. By contrast, the percentage of peripheral
\end{abstract}

Correspondence to: Professor Yan Zhou, Department of Laboratory Medicine, Lianyungang Hospital Affiliated to Bengbu Medical College, 41 Hailian Street, Lianyungang, Jiangsu 222006, P.R. China

E-mail: z-y1022@163.com

*Contributed equally

Abbreviations: EC, esophageal cancer; Bregs, regulatory B cells; Foxp3, forkhead/winged-helix protein; TGF- $\beta$, transforming growth factor- $\beta$; IL-10, interleukin-10; B10, IL-10-producing regulatory $\mathrm{B}$ cell; $\mathrm{Br} 3$, TGF- $\beta$-producing regulatory $\mathrm{B}$ cells

Key words: regulatory B cells, esophageal cancer, interleukin-10, transforming growth factor- $\beta$, forkhead/winged-helix protein
IL-10-producing Bregs (B10s) significantly increased in patients with advanced EC following surgery. These findings suggest that Bregs have a negative immunoregulatory role in the development and progression of EC. Furthermore, postoperative combination therapies against Bregs, particularly B10s, may improve the outcome of patients with EC following resection.

\section{Introduction}

Esophageal cancer (EC), the eighth leading cause of cancer-related mortality globally, has a poor prognosis among digestive tract malignancies and an annual diagnosis of approximately half a million individuals worldwide $(1,2)$. The incidence of EC has markedly increased over the past three decades (3). A total of 482,000 new EC cases are diagnosed annually worldwide, resulting in 407,000 mortalities (2). Surgery and radiotherapy are limited to treating local tumors, whereas chemotherapy is limited by toxicity due to its low tumor specificity (1). Considerable evidence suggests that the immune system recognizes and destroys tumor cells, particularly EC cells (4-7).

B cells perform several immunological functions and have been identified to be positive regulators of immune responses and central contributors to the pathogenesis of immune-related diseases as a result of their capacity to produce antigen-specific antibodies (8). However, over the past 30 years, evidence has supported a negative regulatory function for B cells $(8,9)$. Advances in B-cell biology have demonstrated that regulatory B cells (Bregs) release numerous cytokines, with certain Bregs involved in the production of negative regulatory cytokines, including interleukin (IL)-10 (B10s) and transforming growth factor $\beta$ (TGF- $\beta$ ) (Br3s), and others expressing the transcription factor forkhead box protein 3 (Foxp3) (10). Previous studies have demonstrated that Bregs have a significant role in the development and resolution of numerous chronic diseases, including experimental autoimmune encephalomyelitis, inflammatory bowel disease and contact hypersensitivity (11-13). The regulatory mechanisms associated with Bregs in the immune system include protection from lethal inflammation, modulation of 
the development of autoimmune diseases (13-15) and inhibition of anti-tumor responses in various tumor models (16-19). However, few studies have assessed the role of Bregs in EC development.

While evidence has indicated the importance of Bregs in tumor development, there has, to the best of our knowledge, been no research into the functions of Bregs in cancer, particularly in patients with EC (20). The present study investigated the perioperative changes in the Bregs in patients with EC and the association between these cells and clinical phenotypes.

\section{Material and methods}

Patient selection. A total of 60 patients with EC were recruited into this case-control study, including 36 males and 24 females with an age range of 50-70 years and a mean age of 64 years. Patients with EC were recruited from the Department of Cardiothoracic Surgery, Lianyungang Hospital Affiliated to Bengbu Medical College (Lianyungang, China). All cases of EC had been histologically confirmed prior to the study. None of the patients with EC had received any invasive treatment, such as radiotherapy or neoadjuvant chemotherapy, prior to tumor resection. Patients with EC were analyzed using the seventh edition of the American Joint Committee on Cancer tumor, node and metastasis staging system in EC for the assessment of disease severity (21). Age- and gender-matched healthy controls were recruited from the Medical Examination Centre of Lianyungang Hospital Affiliated to Bengbu Medical College between July 2011 and July 2012. None of the subjects had a history of autoimmune diseases or tumors.

This study was approved by the Ethical Committee of Lianyungang Hospital Affiliated to Bengbu Medical College (no. 2011-108) and was conducted in compliance with the Declaration of Helsinki. All participants were informed about the investigative nature of the study and signed an informed consent document prior to enrollment in the study.

Sample collection and preparation. Peripheral blood samples were obtained from venous blood immediately subsequent to admission but prior to treatment intervention, in addition to at one and seven days after tumor resection. Peripheral blood mononuclear cells (PBMCs) were isolated from the peripheral blood samples using density gradient separation. Whole blood samples were overlaid onto Ficoll ${ }^{\circledR}$ separation media (GE Healthcare, Waukesha, WI, USA) following 1:1 dilution with Hank's Balanced Salt Solution (Gibco-BRL, Carlsbad, CA, USA). PBMCs were then centrifuged at 1,500 x $\mathrm{g}$ for $30 \mathrm{~min}$, collected at the plasma interface and washed three times following centrifugation at $1,500 \mathrm{x}$ for $10 \mathrm{~min}$.

The isolated PBMCs were resuspended in a complete RPMI-1640 GlutaMax ${ }^{\mathrm{TM}}$ medium (Gibco-Invitrogen, Breda, The Netherlands) at $5 \times 10^{6}$ cells $/ \mathrm{ml}$ in two Falcon ${ }^{\mathrm{TM}}$ tubes. GolgiPlug $^{\mathrm{TM}}$ (BD Biosciences, San Jose, CA, USA) was then added to each tube and cells were incubated for $5 \mathrm{~h}$ in $5 \% \mathrm{CO}_{2}$ at $37^{\circ} \mathrm{C}$. Following incubation, PBMCs were stained for $15 \mathrm{~min}$ in the dark using phycoerythrin-labeled anti-cluster of differentiation (CD) 19 and fluorescein isothiocyanate-labeled anti-CD5 (BD Biosciences) monoclonal antibodies. PBMCs were then permeabilized/fixed using the FIX\&PERM ${ }^{\circledR}$ kit (ADG, Kaumberg, Austria). Cells were successively stained for $15 \mathrm{~min}$ in the dark using allophycocyanin-labeled anti-IL-10 and -TGF- $\beta 1$ monoclonal antibodies and peridinin chlorophyll-cyanine5.5-labeled anti-FOXP3 monoclonal antibodies (BD Biosciences), prior to washing once with phosphate-buffered saline (PBS). Cells were resuspended in $500 \mu 1$ PBS prior to flow cytometric analysis.

Flow cytometry. Flow cytometric analysis was conducted using a BD FACSCalibur flow cytometer (BD Biosciences). For the analysis of Bregs, the acquisition and analysis gates were restricted to the live lymphocyte population. For myeloid-derived suppressor cell analysis, all live cells were included. $\mathrm{CD}^{+} \mathrm{CD} 19^{+}$cells were calculated as the percentage of live CD19+ lymphocytes. Bregs were identified as $\mathrm{CD}^{+} \mathrm{CD} 19^{+}$cells and the production of IL-10, FOXP3 and TGF $\beta 1$ was calculated as the percentage of cytokines.

Statistical analysis. All values are presented as the mean \pm standard error of the mean. Statistical analyses were performed using SPSS 11.0 statistical software (SPSS Inc., Chicago, IL, USA). The percentage of Bregs among the groups was analyzed using one-way analysis of variance, followed by an unpaired student's t-test. A value of $\mathrm{P}<0.05$ was considered to indicate a statistically significant difference.

\section{Results}

Perioperative changes in peripheral Bregs. As shown in Fig. 1, the percentage of peripheral Bregs in patients with EC prior to surgery (ECb) was observed to be significantly higher than that in the group of healthy controls (3.40 \pm 0.60 vs. $1.76 \pm 0.23 \%$; $\mathrm{P}<0.05)$. No significant difference was observed in the percentage of Bregs between patients with EC at one day after surgery (ECa1) and the ECb group (2.99 \pm 0.39 vs. $3.40 \pm 0.60 \%$; P>0. 05; Fig. 1). However, a significant reduction in the percentage of Bregs was observed in patients with $\mathrm{EC}$ at seven days after tumor resection (ECa7) compared with the $\mathrm{ECb}(1.92 \pm 0.39$ vs. $3.40 \pm 0.60 \%$; $\mathrm{P}<0.05$; Fig. 1) and $\mathrm{ECa} 1$ (1.92 \pm 0.39 vs. $2.99 \pm 0.39 \%$; $\mathrm{P}<0.05$; Fig. 1$)$ groups.

Perioperative changes in peripheral B10s. As shown in Fig. 2, the percentage of B10s in the ECb group was observed to be significantly higher than that in the healthy controls $(2.52 \pm 0.41$ vs. $1.56 \pm 0.28 \% ; \mathrm{P}<0.05)$. Furthermore, the percentage of $\mathrm{B} 10 \mathrm{~s}$ in the patients with EC significantly increased over time following tumor resection $(3.59 \pm 0.29 \%$ in ECa1 vs. $8.36 \pm 0.51 \%$ in $\mathrm{ECa} 7 \mathrm{P}<0.05)$.

Perioperative changes in peripheral $\mathrm{Br} 3 \mathrm{~s}$. The percentage of $\mathrm{Br} 3 \mathrm{~s}$ in the ECb group was not observed to be significantly different from that of the healthy controls $(6.13 \pm 0.57$ vs. $5.91 \pm 0.23 \%$; P>0.05; Fig. 3). However, the percentage of $\mathrm{Br} 3 \mathrm{~s}$ was observed to decrease in the ECa1 group compared with the ECb group $(4.54 \pm 0.41$ vs. $6.13 \pm 0.57 \%)$ prior to increasing in the ECa7 group $(5.61 \pm 0.42 \%)$. The percentage of $\mathrm{Br} 3 \mathrm{~s}$ in the $\mathrm{ECa} 7$ group remained below that in the $\mathrm{ECb}$ group, although the difference was not significant $(\mathrm{P}>0.05)$ (Fig. 3).

Perioperative changes in peripheral Foxp3-expressing Bregs. As shown in Fig. 4, the percentage of Foxp3-expressing Bregs 

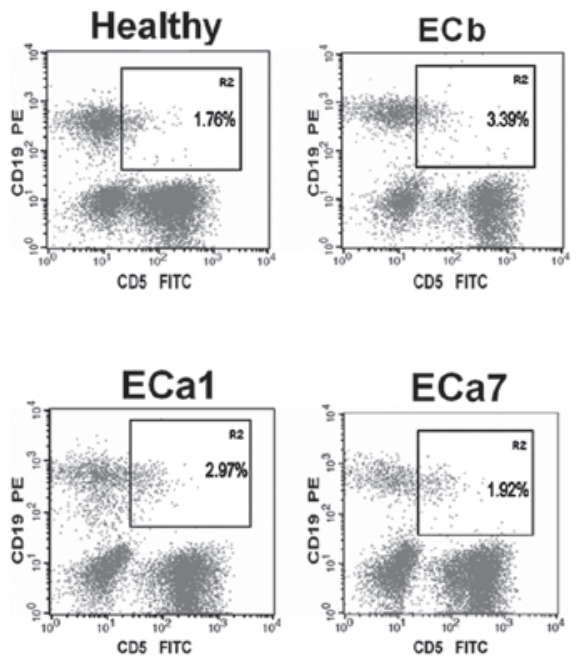

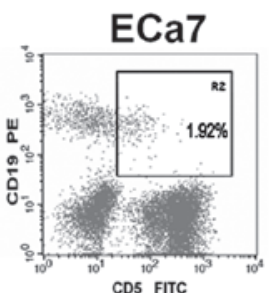

B

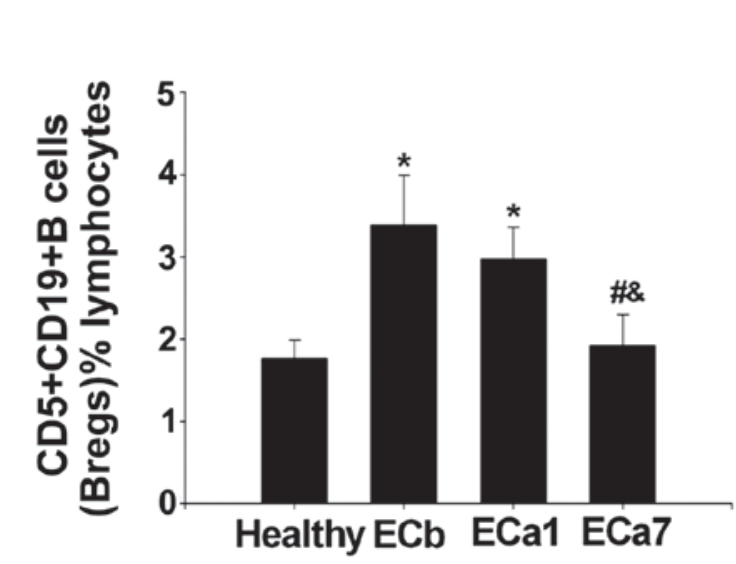

Figure 1. Percentage of peripheral Bregs $\left(\mathrm{CD} 5^{+} \mathrm{CD} 19^{+}\right.$cells) in the study groups. The percentage of peripheral Bregs was determined in healthy controls (Healthy) and patients with EC prior to surgery (ECb), at one day (ECa1) and at seven days after surgery (ECa7). (A) Flow cytometric analysis of peripheral Bregs with a representative percentage of Breg cells indicated for each group. (B) Percentage of Bregs in the total lymphocyte population in peripheral blood. Data are presented as the mean \pm standard error of the mean. ${ }^{*} \mathrm{P}<0.05$ vs. the Healthy group; ${ }^{~} \mathrm{P}<0.05$ vs. the ECb group and ${ }^{\circledR} \mathrm{P}<0.05$ vs. the ECa1 group. Bregs, regulatory B cells; EC, esophageal cancer; CD, cluster of differentiation; FITC, fluorescein isothiocyanate; PE, phycoerythrin.

A
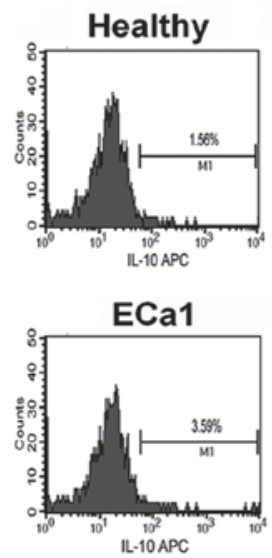

B
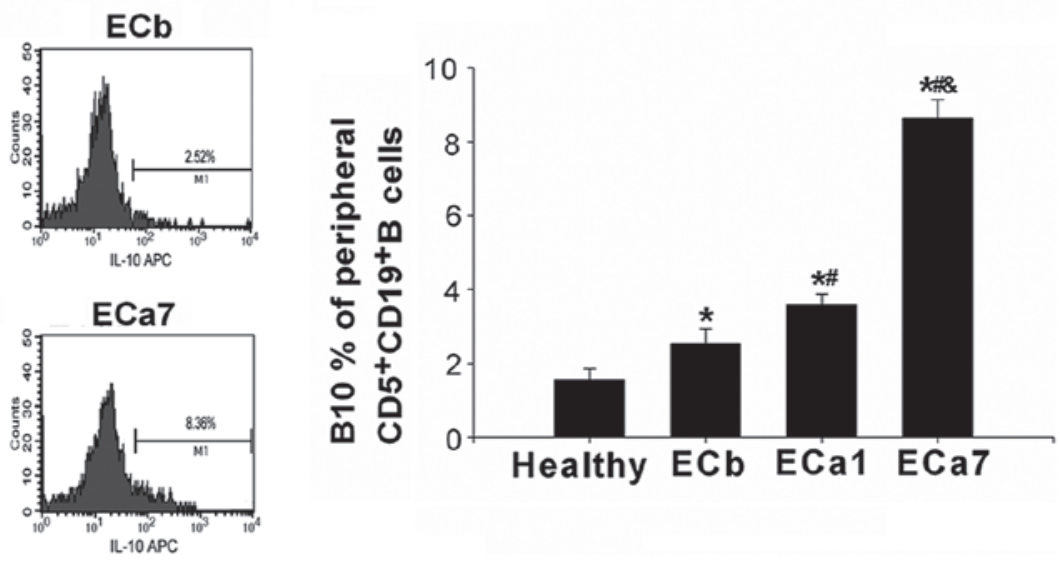

Figure 2. Percentage of peripheral B10s in the study groups. The percentage of peripheral B10s was determined in healthy controls (Healthy) and in patients with EC prior to surgery (ECb), at one day (ECa1) and at seven days after surgery (ECa7). (A) Flow cytometric analysis of peripheral B10s with a representative percentage of B10 cells indicated for each group. (B) Percentage of B10s in the total Breg population in peripheral blood. Data are presented as the mean \pm standard error of the mean. ${ }^{*} \mathrm{P}<0.05$ vs. the Healthy group; ${ }^{~} \mathrm{P}<0.05$ vs. the ECb group and ${ }^{\circledR} \mathrm{P}<0.05$ vs. the ECa1 group. Bregs, regulatory $\mathrm{B}$ cells $\left(\mathrm{CD}{ }^{+} \mathrm{CD} 19^{+}\right.$cells); B10, IL-10-producing Breg; EC, esophageal cancer; IL, interleukin; APC, allophycocyanin.

was observed to be significantly higher in the ECb group than that in the healthy controls $(8.35 \pm 1.04$ vs. $2.91 \pm 0.23 \%$; $\mathrm{P}<0.05)$. However, the percentage of Foxp3-expressing Bregs was shown to significantly decrease over time following tumor resection $(8.35 \pm 1.04$ in $\mathrm{ECb}$ vs. $4.84 \pm 0.16$ in $\mathrm{ECa} 1$ and $4.02 \pm 0.66 \%$ in ECa7; $\mathrm{P}<0.05)$. The frequency of Foxp3-expressing Bregs was observed to be lower in the ECa7 group compared with that in the ECa1 group; however, this difference was not significant (4.84 \pm 0.16 vs. $4.02 \pm 0.66 \%$; P>0.05) (Fig. 4).

\section{Discussion}

As a functionally unique subgroup of B lymphocytes, Bregs promote tumor progression in various malignancies, including sarcomas, melanomas, breast carcinomas and hepatocellular carcinomas $(5,22,23)$. However, current studies on Bregs have been predominantly conducted using animal models. Thus, the disease-specific patterns of peripheral Bregs in patients with $\mathrm{EC}$ are yet to be elucidated. The present study investigated the functions of $\mathrm{CD}^{+} \mathrm{CD} 19^{+} \mathrm{B}$-cell-derived IL-10, TGF- $\beta$ and FOXP3 in patients with EC.

IL-10 is a 178 -amino acid protein secreted by various cells, primarily Type 2 helper T-cell (Th2) clones (24). IL-10 has multiple functions in immune modulation and exhibits anti-inflammatory and suppressive effects on hematopoietic cells (17). A number of studies have identified IL-10-producing $\mathrm{CD} 19^{+} \mathrm{B}$ cells, which are known as B10s $(8,10,12)$. Lee et al $(25,26)$ described human IL-10-producing Bregs that 
A
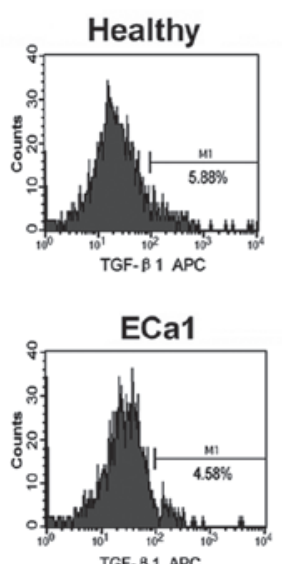

TGF- $\beta 1$ APC
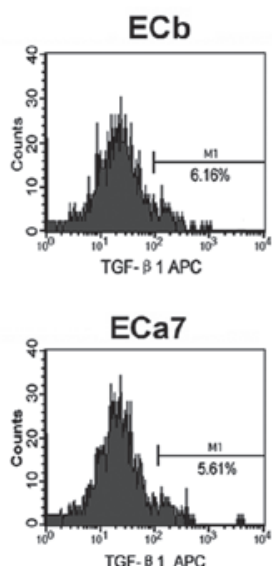

B

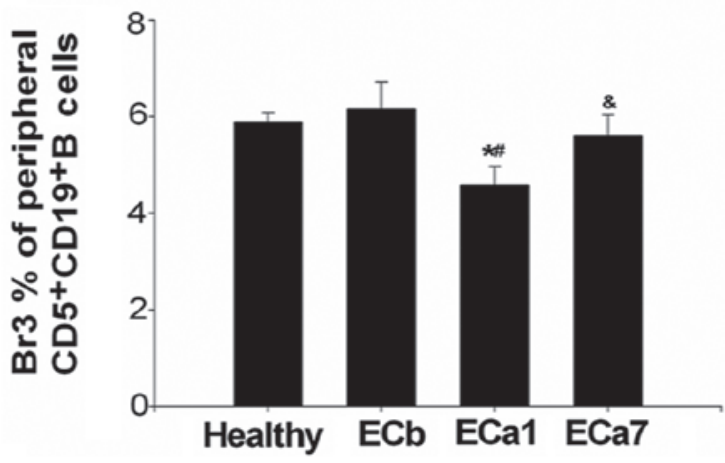

Figure 3. Percentage of peripheral Br3s in the study groups. The percentage of peripheral Br3s was determined in healthy controls (Healthy) and in patients with EC prior to surgery (ECb), at one day (ECa1) and at seven days after surgery (ECa7). (A) Flow cytometric analysis of peripheral Br3 with a representative percentage of Br3 cells indicated for each group. (B) Percentage of Br3 in the total Breg population in peripheral blood. Data are presented as the mean \pm standard error of the mean. "P $>0.05$ vs. the Healthy group; ${ }^{~} \mathrm{P}>0.05$ vs. the ECb group and ${ }^{\&} \mathrm{P}<0.05$ vs. the ECa1 group. Bregs, regulatory B cells $\left(\mathrm{CD}{ }^{+} \mathrm{CD} 19^{+}\right.$cells); $\mathrm{Br} 3$, TGF- $\beta$-producing regulatory $\mathrm{B}$ cell; EC, esophageal cancer; TGF- $\beta$; transforming growth factor- $\beta$; APC, allophycocyanin.

A
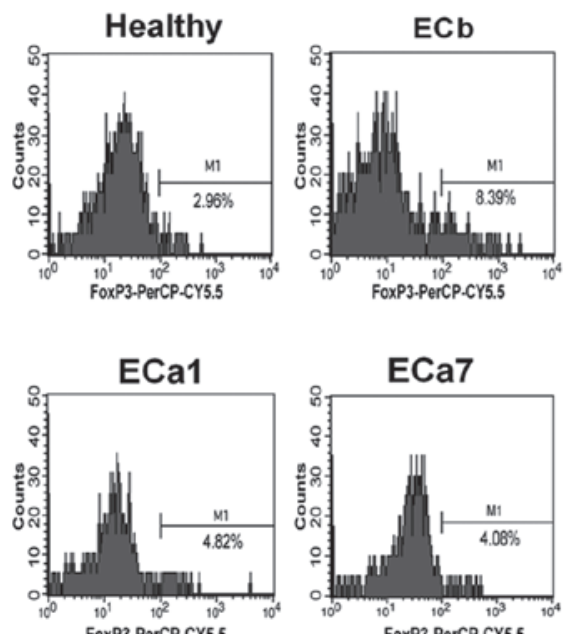

FoxP3-PerCP-CY5.5

B

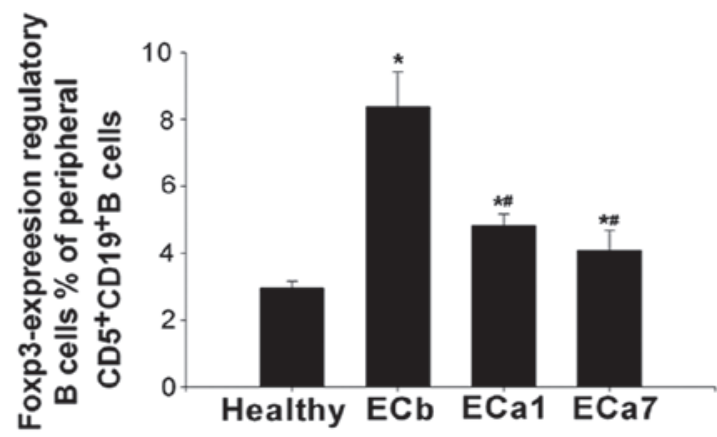

Figure 4. Percentage of peripheral Foxp3-expressing Bregs in the study groups. The percentage of peripheral Foxp3-expressing Bregs were determined in healthy controls (Healthy) and in patients with EC prior to surgery (ECb), at one day (ECa1) and at seven days after surgery (ECa7). (A) Flow cytometric analysis of peripheral Foxp3-expressing Bregs with a representative percentage of Foxp3-expressing cells indicated for each group. (B) Percentage of Foxp3-expressing Bregs in the total Breg population in peripheral blood. Data are presented as the mean \pm standard error of the mean. ${ }^{*} \mathrm{P}<0.05$ vs. the Healthy group; ${ }^{~} \mathrm{P}<0.05$ vs. the ECb group. Bregs, regulatory B cells (CD5 ${ }^{+} \mathrm{CD} 19^{+}$cells); EC, esophageal cancer; Foxp3, forkhead box protein 3; PerCP-Cy5.5, peridinin chlorophyll-cyanine5.5.

expressed a $\mathrm{CD}^{+} \mathrm{CD} 19^{+}$phenotype in PBMCs. The present study demonstrated that the percentage of B10s was higher in patients with EC than that in healthy controls and was markedly increased following surgery, with the in the ECa7 group exceeding that in the ECal group. These findings are consistent with the significant perioperative changes observed in peripheral Bregs in patients with hepatocellular carcinoma reported by Chen et al (23).

TGF- $\beta$ belongs to a superfamily of cytokines that regulates cell proliferation and differentiation, developmental patterning and morphogenesis, and disease pathogenesis (24). TGF- $\beta 1$ plays critical roles in tumor development through its influence on the apoptotic pathways (27-29). Miller et al (30) demonstrated that TGF- $\beta 1$ is crucial in the progression of
EC due to the fact that it induces the activation of extracellular signal-regulated protein kinases 1 and 2 . In a study by Tian et al (31), an additional Breg subgroup, which produced TGF- $\beta 1$ following in vitro stimulation with lipopolysaccharides, was identified. Furthermore, Lee et al (32) recently reported the presence of $\mathrm{Br} 3 \mathrm{~s}$ in human peripheral blood. The present study revealed that the percentage of peripheral $\mathrm{Br} 3 \mathrm{~s}$ was higher in patients with EC than that in healthy controls. In addition, the percentage of $\mathrm{Br} 3 \mathrm{~s}$ was observed to markedly increase following surgery in patients with EC. Therefore, the systemic inflammatory state induced by EC cells may promote peripheral $\mathrm{Br} 3$ production.

Foxp3 is a transcription factor that controls the development of regulatory $\mathrm{T}$ cells and is reported to be expressed in 
mouse $\mathrm{CD}^{+} \mathrm{T}$ cells (33). CD $4^{+} \mathrm{Foxp}^{+} \mathrm{T}$ cells are known as Tregs and are involved in the negative regulation of immune responses (33). A study by Huang and $\mathrm{Fu}$ (7) reported that $\mathrm{CD} 4{ }^{+} \mathrm{Foxp}^{+} \mathrm{T}$ cells are present in EC tissues at levels 10 -fold higher than those in non-EC tissues. Furthermore, Wang et al (34) demonstrated that FOXP3 is overexpressed in EC cells, but not found in normal esophageal mucosal cells. A study has also indicated that $\mathrm{CD}^{+} \mathrm{CD} 19^{+} \mathrm{Foxp} 3^{+}$Bregs are present among human PBMCs (35). The results of the present study demonstrate that the percentage of peripheral $\mathrm{CD}^{+} \mathrm{CD} 19^{+} \mathrm{Foxp} 3^{+}$Bregs is higher in patients with $\mathrm{EC}$ than that in healthy controls. Furthermore, the percentage of $\mathrm{CD}^{+} \mathrm{CD} 19^{+} \mathrm{Foxp} 3^{+}$Bregs was observed to significantly decrease in patients with EC following surgery. However, the percentage of these cells in the peripheral blood of the ECa7 group was not observed to differ significantly from that of the ECa1 group. These results suggest that FOXP3 overexpression may be significantly correlated with tumor staging and lymph node metastasis.

To the best of our knowledge, the present study is the first to demonstrate the perioperative changes in circulating Bregs in patients with EC prior to and following radical surgery. Further studies are required to determine whether the increases in circulating Bregs following surgery are a consequence of the tumor removal or of the extensive esophageal surgery. The mediators of $\mathrm{Br} 1, \mathrm{Br} 3$ and Bregs should be profiled and validated in order to elucidate the mechanisms associated with their interactions. Network biomarkers that show protein-protein interactions within these regulatory cells should be investigated based on protein annotations, interactions and signaling pathways $(36,37)$.

In conclusion, the current study demonstrated that the percentage of peripheral Br3s and Foxp3-expressing Bregs decreased following surgery in patients with EC, whereas the percentage of circulating B10s was significantly increased in patients with advanced EC following surgery. Furthermore, Foxp3 and TGF- $\beta$ may be involved in regulating the number and function of Bregs in patients with advanced EC who undergo surgery. The findings of the present study suggest that, in patients with EC, the level of IL-10 reduced to the levels of healthy controls via medical intervention, therefore this may confer an enhanced prognosis following surgery.

\section{Acknowledgements}

This study was supported by a grant from the Department of Science \& Technology, Lianyungang, Jiangsu, P.R. China (no. SH1008).

\section{References}

1. Kamangar F, Dores GM and Andeson WF: Patterns of cancer incidence, mortality, and prevalence across five continents: defining priorities to reduce cancer disparities in different geographic regions of the world. J Clin Oncol 24: 2137-2150, 2006.

2. Ferlay J, Shin HR, Bray F, Forman D, Mathers C and Parkin DM: Estimates of worldwide burden of cancer in 2008: GLOBOCAN 2008. Int J Cancer 127: 2893-2917, 2010.

3. Enzinger PC and Mayer RJ: Esophageal Cancer. N Engl J Med 349: 2241-2252, 2003.

4. Watanabe R, Ishiura N, Nakashima H, Kuwano Y, Okochi H, Tamaki K, Sato S, Tedder TF and Fujimoto M: Regulatory B cells (B10 cells) have a suppressive role in murine lupus: CD19 and B10 cell deficiency exacerbates systemic autoimmunity. J Immunol 184: 4801-4809, 2010.
5. Olkhanud PB, Damdinsuren B, Bodogai M, Gress RE, Sen R, Wejksza K, Malchinkhuu E, Wersto RP and Biragyn A: Tumor-evoked regulatory $\mathrm{B}$ cells promote breast cancer metastasis by converting resting $\mathrm{CD} 4^{+} \mathrm{T}$ cells to T-regulatory cells. Cancer Res 71: 3505-3515, 2011.

6. Schioppa T, Moore R, Thompson RG, Rosser EC, Kulbe H, Nedospasov S, Mauri C, Coussens LM and Balkwill FR: $\mathrm{B}$ regulatory cells and the tumor promoting actions of TNF- $\alpha$ during squamous carcinogenesis. Proc Natl Acad Sci USA 108: 10662-10667, 2011.

7. Huang $\mathrm{C}$ and $\mathrm{Fu} \mathrm{ZX}$ : Localization of $\mathrm{IL}-17^{+} \mathrm{Foxp} 3^{+} \mathrm{T}$ cells in esophageal cancer. Immunol Invest 40: 400-412, 2011.

8. Mauri C and Bosma A: Immune regulatory function of B cells. Annu Rev Immunol 30: 221-241, 2012.

9. Lund FE and Randall TD: Effector and regulatory B cells: modulators of $\mathrm{CD}^{+} \mathrm{T}$ cell immunity. Nat Rev Immunol 10: 236-247, 2010.

10. Noh G and Lee JH: Regulatory B cells and allergic diseases. Allergy Asthma Immunol Res 3: 168-177, 2011.

11. Watanabe R, Fujimoto M, Ishiura N, Kuwano Y, Nakashima H, Yazawa N, Okochi H, Sato S, Tedder TF and Tamaki K: CD19 expression in B cells is important for suppression of contact hypersensitivity. Am J Pathol 171: 560-570, 2007.

12. Yanaba K, Bouaziz JD, Haas KM, Poe JC, Fujimoto M and Tedder TF: A regulatory B cell subset with a unique $\mathrm{CD} 1 \mathrm{dhiCD} 5^{+}$ phenotype controls $\mathrm{T}$ cell-dependent inflammatory responses. Immunity 28: 639-650, 2008.

13. Matsushita T, Yanaba K, Bouaziz JD, Fujimoto M and Tedder TF: Regulatory B cells inhibit EAE initiation in mice while other B cells promote disease progression. J Clin Invest 118: 3420-3430, 2008.

14. Fillatreau S, Sweenie CH, McGeachy MJ, Gray D and Anderton SM: B cells regulate autoimmunity by provision of IL-10. Nat Immunol 3: 944-950, 2002.

15. Mizoguchi A, Mizoguchi E, Takedatsu H, Blumberg RS and Bhan AK: Chronic intestinal inflammatory condition generates IL-10-producing regulatory B cell subset characterized by CD1d upregulation. Immunity 16: 219-230, 2002.

16. Fillatreau S, Gray D and Anderton SM: Not always the bad guys: B cells as regulators of autoimmune pathology. Nat Rev Immunol 8: 391-397, 2008.

17. DiLillo DJ, Matsushita T and Tedder TF: B10 cells and regulatory B cells balance immune responses during inflammation, autoimmunity, and cancer. Ann NY Acad Sci 1183: 38-57, 2010.

18. Mauri $\mathrm{C}$ and Ehrenstein MR: The 'short' history of regulatory B cells. Trends Immunol 29: 34-40, 2008.

19. Mizoguchi A and Bhan AK: A case for regulatory B cells. J Immunol 176: 705-710, 2006.

20. Mosser D and Zhang X: Interleukin-10: new perspectives on an old cytokine. Immunol Rev 226: 205-218, 2008.

21. Edge S, Byrd DR, Compton CC, Fritz AG, Greene FL and Trotti A (eds): AJCC Cancer Staging Manual. Seventh edition. Springer, New York, NY, 2010.

22. Inoue S, Leitner WW, Golding B and Scott D: Inhibitory effects of B cells on antitumor immunity. Cancer Res 66: 7741-7747, 2006.

23. Chen T, Song D, Min Z, et al: Perioperative dynamic alterations in peripheral regulatory $\mathrm{T}$ and $\mathrm{B}$ cells in patients with hepatocellular carcinoma. J Transl Med 10: 14, 2012.

24. Im SH, Hueber A, Monticelli S, Kang KH and Rao A: Chromatin-level regulation of the IL10 gene in T cells. J Biol Chem 279: 46818-46825, 2004.

25. Lee JH, Noh J, Noh G, Choi WS and Lee SS: IL-10 is predominantly produced by the CD19(low)CD5(+) regulatory B cell subpopulation: characterization of CD19(high) and CD19(low) subpopulations of CD5(+) B cells. Yonsei Med J 52: 851-855, 2011.

26. Lee JH, Noh J, Noh G, Kim HS, Mun SH, Choi WS, Cho S and Lee S: Allergen-specific B cell subset responses in cow's milk allergy of late eczematous reactions in atopic dermatitis. Cell Immunol 262: 44-51, 2010.

27. Itoh $S$ and Itoh F: Implication of TGF- $\beta$ as a survival factor during tumour development. J Biochem 151: 559-562, 2012.

28. Hoshino Y, Katsuno Y, Ehata S and Miyazono K: Autocrine TGF- $\beta$ protects breast cancer cells from apoptosis through reduction of BH3-only protein, Bim. J Biochem 149: 55-65, 2011.

29. Edlund S, Bu S, Schuster N, Aspenström P, Heuchel R, Heldin NE, ten Dijke P, Heldin $\mathrm{CH}$ and Landström M: Transforming growth factor-betal (TGF-beta)-induced apoptosis of prostate cancer cells involves Smad7-dependent activation of p38 by TGF-beta-activated kinase 1 and mitogen-activated protein kinase kinase 3. Mol Biol Cell 14: 529-544, 2003. 
30. Miller AV, Alvarez SE, Spiegel S and Lebman DA. Sphingosine kinases and sphingosine-1-phosphate are critical for transforming growth factor beta-induced extracellular signal-regulated kinase 1 and 2 activation and promotion of migration and invasion of esophageal cancer cells. Mol Cell Biol 28: 4142-4151, 2008.

31. Tian J, Zekzer D, Hanssen L, Lu Y, Olcott A and Kaufman DL: Lipopolysaccharide-activated B cells down-regulate Th1 immunity and prevent autoimmune diabetes in nonobese diabetic mice. J Immunol 167: 1081-1089, 2001.

32. Lee JH, Noh J, Noh G, Choi WS, Cho S and Lee SS: Allergen-specific transforming growth factor- $\beta$-producing $\mathrm{CD} 19^{+} \mathrm{CD}^{+}$regulatory $\mathrm{B}$-cell $(\mathrm{Br} 3)$ responses in human late eczematous allergic reactions to cow's milk. J Interferon Cytokine Res 31: 441-449, 2011.
33. Hori S, Nomura T and Sakaguchi S: Control of regulatory T cell development by the transcription factor Foxp3. Science 299: 1057-1061, 2003.

34. Wang G, Liu G, Liu Y, Li X and Su Z: FOXP3 Expression in esophageal cancer cells is associated with poor prognosis in esophageal cancer. Hepatogastroenterology 59: 2186-2191, 2012.

35. Noh J, Choi WS, Noh G and Lee JH: Presence of Foxp3-expressing CD19(+)CD5(+) B Cells in human peripheral blood mononuclear cells: Human CD19(+)CD5(+)Foxp3(+) regulatory B cell (Breg). Immune Netw 10: 247-249, 2010.

36. Baumgartner $\mathrm{C}$, Osl $\mathrm{M}$, Netzer $\mathrm{M}$ and Baumgartner $\mathrm{D}$ : Bioinformatic-driven search for metabolic biomarkers in disease. J Clin Bioinforma 1: 2, 2011.

37. Wang $X$ and Liotta L: Clinical bioinformatics: a new emerging science. J Clin Bioinforma 1: 1, 2011. 